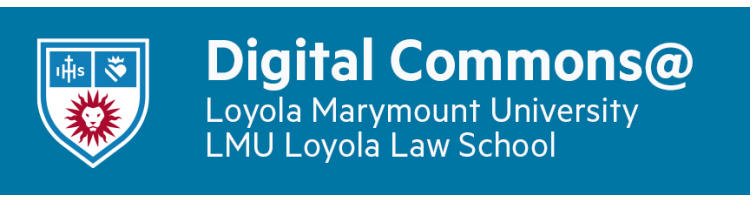

Journal of Catholic Education

3-1-2005

\title{
Mentorship: Toward Success in Teacher Induction and Retention
}

\author{
Sonya Vierstraete
}

Follow this and additional works at: https://digitalcommons.Imu.edu/ce

\section{Recommended Citation}

Vierstraete, S. (2005). Mentorship: Toward Success in Teacher Induction and Retention. Journal of Catholic Education, 8 (3). http://dx.doi.org/10.15365/joce.0803072013

This Review of Research is brought to you for free with open access by the School of Education at Digital Commons at Loyola Marymount University and Loyola Law School. It has been accepted for publication in Journal of Catholic Education by the journal's editorial board and has been published on the web by an authorized administrator of Digital Commons at Loyola Marymount University and Loyola Law School. For more information about Digital Commons, please contact digitalcommons@lmu.edu. To contact the editorial board of Journal of Catholic Education, please email JCE@nd.edu. 


\title{
REVIEW OF RESEARCH
}

\section{MENTORSHIP: \\ TOWARD SUCCESS IN TEACHER \\ INDUCTION AND RETENTION}

\author{
SONYA VIERSTRAETE \\ Holy Redeemer Catholic School, Marshall, Minnesota
}

The mentoring of new teachers has proven to be an effective strategy in helping novice teachers succeed. This essay provides an overview of mentorship and suggests concrete, research-based techniques for implementing a mentorship program.

$\mathrm{M}$ entoring is an important issue in education today and a favored strategy in the United States as an element in teacher induction (FeimanNemser, 1996). Nearly $30 \%$ of beginning teachers will leave the profession within the first 5 years of their career (Boreen, Johnson, Niday, \& Potts, 2000), and according to Gonzales and Sosa (1993), it is often the most creative and talented new educators who exit the profession. The "exodus," it seems, is even greater in some school districts (Halford, 1998, p. 33), and if we want "to retain new teachers, we must do two things: design good schools in which to teach and employ mentoring" (p. 34). Before further examining current mentorship purposes and practices, however, the history of mentorship must be reviewed. The review of literature is presented in the following three sections: A History of Mentorship, Purpose and Importance of Mentorship, and the Role of the Principal.

\section{HISTORY OF MENTORSHIP}

Mentorship has roots that date back to ancient times and "has served as a powerful developer of human potential throughout the centuries" (Bey \& Holmes, 1992, p. 19). The term “mentor" had its origin in Homer's Odyssey. Mentor was a wise and learned individual who was the friend of Odysseus, a Greek king. Mentor became entrusted with the education of Odysseus' son, Telemachus, to be his guide and companion (Bey \& Holmes, 1990; Podsen \& Denmark, 2000). Today, mentors are thought to be guides and companions along the lines of a protégé or an apprentice. 
There are other historical figures of noted mentors. Socrates and Plato were paired as mentor and protégé as were Plato and Aristotle. Drever (1912) discussed Socrates' mentoring of Plato as an illustration of learning from a master; Plato was considered an actual and professed disciple of Socrates. He developed an aspect of the Socratic educational theory that appealed to him. Because of a mentoring relationship, it was not necessary for Plato to replicate Socrates' work nor was it necessary for Aristotle to repeat Plato entirely. Drever continued, "Essentially Aristotle agrees with Plato, but he is much clearer and more emphatic as regards the part which training plays in the development of practical morality" (p. 88). Burnett (1967) described Aristotle's view of education and mentoring as "the soul of the student must be worked over first, like land that is to nourish seed, by a training of the character to enjoy aright and hate aright" (p. 95). The protégé is led by the mentor to develop his or her own beliefs. Frankena (1965) also discussed Aristotle's view as, "recognizing the importance of activity and interest in education....Men learn some things by habituation and some by instruction" (p. 55). Frankena further reflected on Aristotle's perspective:

In general, education must prefer the higher to the lower and the end to the means, remembering in this connection that the lower is always a means to the higher, which is its end. So education must cultivate the lower for the sake of the higher - the body for the sake of the soul, the irrational part of the soul for the sake of the rational, the practical intellect for the sake of the theoretical....Education must prepare [people] to do what is necessary. $(1965$, p. 64)

The mentor sets the example and guides the protégé to develop into a successful individual in his or her own respect.

Another historical educational mentor is found in the writings of Rousseau (1883). In Emile, Rousseau wrote that,

We are born weak, we need strength; we are born destitute of all things, we need assistance; we are born stupid, we need judgment. All that we have not at our birth, and that we need when grown up, is given us by education. This education comes to us from nature itself, or from other men, or from circumstances. The internal development of our faculties and of our organs is the education nature gives us; the use we are taught to make of this development is the education we get from other men; and what we learn, by our own experience, about things that interest us, is the education of circumstances. (p. 12)

Rousseau placed significant importance on education. It is necessary, he felt, that people learn from nature, others, and experience (Compayre, 1907). For Rousseau, mentorship was education from others. Mentors are our teachers.

Although the specific needs within education change over the ages, the 
theory of mentorship is classical. Mentoring is a clear example of using lessons from the past to improve contemporary practice. Building a knowledge base on which to create a theoretical framework to support the practice of modern mentoring is critical for its success in the contemporary world (Nicholls, 1997).

As education continues to evolve, so does the practice of managing a mentorship program. Nicholls (1997) explained that teacher development depends on more than just the individual; instead, it relies upon engagement in the school community. Renewing a commitment to effective mentorships for new teachers is a critical element in this era of school reform.

Education has often followed trends established in the business world, as Boreen and colleagues (2000) noted: "Education, for good or ill, has adopted many of the practices of the business world, including mentoring" (p. 8). The concept of educational mentorship specifically directed toward teachers first began in England during the Industrial Revolution. During this time, new teachers first served as apprentices or pupil teachers. This practice then migrated to the United States in the mid-1880s when apprenticed teachers, with no formal education, were expected to follow in the footsteps of an experienced teacher, replicating the expert's teaching style and methods.

By the 1920s, formal educational courses were required in colleges of education; by the 1950 s, formal teacher education programs became the normal route for certification. Teacher mentorships also grew in popularity: "Formalized support programs for novice teachers have rushed onto the educational landscape during the past decade" (Bey \& Holmes, 1992, p. 79). There has been a rapid growth in the teacher mentorship movement even more recently (Bey \& Holmes, 1992; Head, Reiman, \& Thies-Sprinthall, 1992; Portner, 1998).

\section{PURPOSE AND IMPORTANCE OF MENTORSHIP}

Teacher mentorship can be defined as "helping novices speed up the learning of a new job or skill and reduce the stress of transition, improving instructional performance of novices through modeling by a top performer, and socializing novices into the profession of teaching" (Podsen \& Denmark, 2000, p. 31). Usually, mentorship is the special relationship that is cultivated between a mentor and protégé whereby the mentor counsels, guides, and helps the protégé to develop both personally and professionally (Gardiner, Enomoto, \& Grogan, 2000). The purpose of mentorship efforts range from orientation and induction of new teachers to instructional improvement with an intent to change the culture of the school to a more collaborative learning environment (Podsen \& Denmark, 2000). Heath and Yost explained, "Mentorships have been developed in schools throughout the 
nation in an attempt to stem the departure of first-year teachers" (2001, p. $25)$. It seems that the first year of teaching has greater correlation to teacher retention than either prior academic performance or the quality of the teacher preparation program (Boreen et al., 2000).

It is important to focus on the reasons that mentors accept the responsibility and challenge of mentoring. "Becoming a mentor allows us to repay the debt we owe to our own mentors, or, if our early years of teaching were painful, to spare other new teachers the same fate" (Boreen et al., 2000, p. 2). Participating in a mentorship allows teachers to impact the future of education and how future educators teach. Boreen et al. also suggested that participating in the mentorship experience allows teachers to share their professionalism with several important audiences: local, regional, and national colleagues; administrators; parents; and even students. It is not often that teachers have the opportunity to affirm their status as master teachers publicly. Lastly, mentors also benefit from mentorship relationships. Mentors often report continued contact with their protégés as this experience provides "their richest collegial interactions" (Boreen et al., 2000, p. 3). This relationship can then develop into a peer coaching situation that allows both parties to grow as educators.

According to DePaul (2000), "Well administered mentor programs that foster regular meetings between new teachers and their senior colleagues are lifesavers for first-year teachers" (p. 16). Podsen and Denmark (2000) contributed their notion that the educational community understands that mentors can have a positive effect on novices. Unfortunately, there remains a big gap in deciding what mentors should do, what they actually do, and what novices should learn as a result. Because of this, the roles of the mentor and the protégé, or mentee, need to clearly be defined (Lund, 1992; Podsen \& Denmark, 2000). In order for a mentor to help a protégé be successful, he or she needs to know the necessary expectations from the very start. It is important to define program goals and the role expectations for mentors clearly within the plans established for the mentorship program (Brock, 1999). The mentor should know his or her role as well as the anticipated duration of the mentorship program. The mentor may be seen as a friend or a coach or a role model; all roles are points of reference necessary for a beginning teacher.

The characteristics of a good, quality mentor include being trustworthy, friendly, honest, understanding, empathetic, caring, and willing to share ideas (Podsen \& Denmark, 2000; Portner, 1998). According to Podsen and Denmark, "A central quality of mentoring is that it is intentional, nurturing, insightful, and supportive" (2000, p. 29). These characteristics are not carved in stone, however. The dictionary provides us with other terms for mentoring: guide, supporter, advisor, teacher specialist, teacher coach, consultant, helping teacher, peer teacher, support teacher, encourager, and befriender 
(Podsen \& Denmark, 2000).

Rowley (1999) focused on six basic but essential qualities of a good mentor. Mentors are committed to the role of mentoring. They are accepting of the beginning teacher, skilled at providing instructional support, and effective in different interpersonal contexts. Mentors are also a model of continuous learning and communicate hope and optimism. Mentor teachers are responsible for knowing curriculum content and instructional strategies, as well as other current issues in education. They also need to know how to collaborate with colleagues and how to articulate their beliefs, practices, and goals in ways that are understandable to new teachers. With this as a basis, mentor teachers have the development of a prospective teacher as a primary responsibility (Kyle, Moore, \& Sanders, 1999).

As a mentor's role needs to have definition and clarity, protégé guidelines must also be set. The main characteristic of a protégé is being a novice or new teacher to a school. A protégé works directly with a mentor to become acquainted with the school's environment, culture, and policies. The protégé also works to further develop teaching confidence and skills. Novices need to know that teaching involves a vast array of instructional and professional responsibilities, and they need to be aware of the various reasons for the profession's evolution (Podsen \& Denmark, 2000).

Beginning teachers set high expectations for themselves and others in the school community:

Teachers at this career phase are filled with boundless energy. Finally, after all the professional-preparation courses and field experiences, they are able to stand before a group of students and be called "teachers." Not withstanding feelings of self-doubt, many express their love of the field and a belief that they have the skills necessary to assure that all children assigned to them will achieve at high levels. Above all else, these teachers need mentoring. Without caring, experienced mentors, these enthusiastic apprentice teachers may become disillusioned. (Steffy \& Wolfe, 1998, para. 13)

About one-third of all newly hired teachers leave the field after a few years of teaching (National Commission of Teaching and America's Future, 1996). Unfortunately, these valuable teachers are leaving the profession, not because of a lack of skills and knowledge, but rather, it is their perception of a lack of efficacy (Steffy \& Wolfe, 1998). They feel overwhelmed by the professional demands that exist and do not feel a sense of accomplishment, achievement, and success.

Because of the overwhelming feelings that exist along with high professional demands, mentorship programs need to be implemented as part of beginning teacher induction programs. Steffy and Wolfe (1998) suggested that, with the proper encouragement and mentoring, teachers at this stage 
maintain the euphoria of a beginning teacher in education. If new teachers avoid withdrawal and continue to reflect on experiences, renewal and growth can soon lead the novice teachers to the next level, that of being considered professional teachers.

Teacher induction programs that involve mentoring focus attention on transitions from one stage of teacher development to another (DeBolt, 1992). Podsen and Denmark noted that

Past induction methods have left beginners to flounder on their own without any systematic assistance or encouragement as they have attempted to master these responsibilities. Teacher mentoring may be more than a sensible approach to help keep talented young teachers in the profession. $(2000$, p. 152)

Induction programs paired with mentorship programs successfully integrate new teachers into their assignments and position them more quickly for a focus upon student success.

The term induction itself is not new, although it has a contemporary connotation. DeBolt (1992) expressed the observation that formerly, induction often referred to the informal, often reactionary, and ritualistic socialization of new teachers. Induction now suggests a more sophisticated method of initiating, shaping, and sustaining the first work experience of prospective career teachers. Mentorship programs, as a main component of the induction process, can exist within a range of approaches from an informal, socialization experience to a formalized program with written guidelines and specific expectations for both parties. A comprehensive view of the purposes of induction programs includes providing continuing assistance to reduce the problems known to be common to beginning teachers; supporting development of the knowledge and the skills needed by beginners to be successful in their initial teacher positions; integrating beginning teachers into the social system of the school, district, and community; and, finally, providing an opportunity to analyze and reflect on teaching through a coaching relationship with veteran teachers. Mentoring is a current educational practice becoming more widely incorporated into beginning teacher assistance programs (Bey \& Holmes, 1990).

\section{ROLE OF THE PRINCIPAL}

If mentoring programs are to be successful in lowering teacher attrition rates, administrators must push mentorship programs beyond socialization by matching new teachers with competent mentors who can assist with the "ongoing process of planning and teaching lessons, reflecting on the results, and then making informed changes" (Lucas, 1999, p. 45). Steffy and Wolfe (1998) agreed that beginning teachers need to serve an apprenticeship. 
Through reflection, they acquire craft knowledge and internalize meaning about their skills and knowledge. Educators mature through reflection, renewal, and growth. Administrators, especially building principals, are key players in creating mentorship programs that can help new teachers find success.

Brock (1999) offered several steps that principals need to consider in order to develop and manage a successful mentorship program. Steps required in the process of initiating a program include the following: defining the needs of beginning teachers, selecting mentors, defining mentors' roles, providing training for mentors, staying personally involved with both mentors and protégés, and evaluating the program.

When initiating a mentoring program, principals need to solicit the help of teachers on staff. As teachers will be the mentors, their valuable input will help develop a program that is tailored to meet the specific needs of the school setting (VanOverbeke \& Vierstraete, 2001). With the school's needs as well as the teachers' needs in mind, a team of teachers working with the principal needs to create a planning document that delineates the mentorship program for the school.

Given the diversity of beginning teachers, a mentoring program must be responsive to the individual needs of beginning teachers (Brock, 1999). The principal and a team of teachers need to decide on what information new teachers should know about the school in order to be successful. This information can be included in a handbook for new teachers so that they have ready access to information that is often unwritten yet common knowledge to veteran teachers. In addition, Brock (1999), Gordan (1991), and Newton et al. (1994) suggested that a needs assessment questionnaire or checklist be created to use before school begins and be reviewed periodically throughout the year. This assessment provides an opportunity for new teachers to indicate where they need assistance, and it provides principals with valuable information for structuring a program that is responsive to the needs of the beginning teachers (Brock, 1999).

For mentoring to be effective, there must also be a focus on the mentors themselves. An ideal situation would be districts providing support for mentors, tangible incentives, release time, and of course, professional development including tailored coursework (Podsen \& Denmark, 2000; Wood, 1999). Wood stressed that the principal must select mentors on the basis of their interest in forming relationships and assisting new teachers, not on their seniority within the system. These mentors need to be dedicated to coaching new teachers in flexible, nondirective ways. Wood recommended that mentors be matched with new teachers on the basis of school site specifics, including curriculum content, grade-level experience, and specializations including bilingual education and special education. The proximity of mentor and beginning teacher classrooms has also found to be a positive factor 
in successful mentoring relationships (Boreen et al., 2000; Wood, 1999). In addition to Wood's criteria, Newcombe (1988) added that the mentor and protégé should have compatible ideologies about teaching and classroom management, be of the same gender, have an optimal difference of 8 to 10 years of age, and be paired for a specific time period. Podsen and Denmark (2000) suggested that the most important matching criteria are grade level and specific content area. Other researchers have felt, however, that the major issue for new teachers is competence of the mentor rather than specific matching of grade level or subject area (Boreen et al., 2000; Podsen \& Denmark, 2000).

As well meaning as a mentor/protégé pairing might have seemed initially, it may not prove to be a success. Anzul (2000) cautioned that administrators must be prepared to recognize personality conflicts and plan for changes and adjustments in mentoring relationships if problems arise. It may also be necessary to guide the staff through such changes. The matching of the mentor to the protégé is a critical component to the mentoring process. If the match is not optimal, then the mentorship program will not serve the best interests of the new teacher, the mentor, or the school. Differing educational philosophies may be a reason that a match may not be optimal, and this can create obstacles for the mentorship pair (Boreen et al., 2000; Podsen \& Denmark, 2000).

Mismatched mentor relationships will tend to fall apart or fizzle out, and this could leave the beginning teacher without support and alone. DePaul suggested, "If the mentor-mentee relationship isn't working to the benefit of the beginning teacher, he or she should visit with the principal about concerns" (2000, p. 16). According to a number of first-year teachers, it may be beneficial for principals to assign a mentor after the school year begins. That way, the principal can help a mentor select a compatible new teacher or let the mentee select the best-suited mentor (DePaul, 2000).

Training is a necessity when developing any new skill, and mentorship training is essential for a successful and productive program. Each individual involved in the process, including personnel involved in previous mentorship relations, needs to participate in such training. Orientation is the first step for mentors in order to familiarize them with the mentor program; and then, ongoing subsequent sessions should be provided in order to update skills (Brock, 1999). If the school is small, daily meetings and weekly training updates may be too much. On the other hand, in large schools mentors may need to meet more often and in a more formal way to ensure good communication and success. Brock remarked that the school context and goals of the mentorship program should determine the process and substance of the training. It depends on the school climate and size.

The induction of beginning teachers both into the responsibilities of a 
first teaching assignment as well as into the teaching profession is a key task for principals (Brock \& Grady, 1997; Podsen \& Denmark, 2000). Especially in the past 5 years, principals have been the main focus as important instructional leaders within schools. Because of this, the principal needs to demonstrate the importance of the mentorship program by providing encouragement and quality release time for the mentorship pair (Franklin, 2002). Boreen and colleagues (2000) suggested that the school might find time for teachers to confer, plan, and analyze instructional strategies by hiring substitute teachers. The principal is a key component in a mentorship program and needs to be directly involved for the program to succeed. Brock (1999) recommended that the principal initiate the mentorship program by meeting with the new teachers as well as the mentors to clarify expectations including the working relationship of participants and the nonevaluative role of the mentor. The principal also needs to remain involved throughout the mentoring process. The principal, who determines the expectations for teaching and learning, is a key source of support and guidance for beginning teachers (Boreen et al., 2000; Brock, 1999). It is critical that the mentoring relationship does not replace the beginning teacher's relationship with the principal. Boreen et al. suggested that the school principal serve as the mentor's mentor and as a secondary mentor to the beginning teacher. DePaul (2000) added that new teachers who develop a strong bond with their principals reap benefits that extend well past the first year of teaching. A supportive principal plays a key role in helping first-year teachers find a mentor, take part in professional development, and make full use of planning time. Mentors will want to model and encourage a good working relationship with administrators. They can help develop a good relationship between the beginning teacher and the administrator by discussing and modeling effective teacher/administrator relationships during the initial mentoring sessions (Anzul, 2000; Boreen et al., 2000). Anzul has written that the administrator and mentor should become partners in helping the new teacher find success and quickly integrate into the culture of the school.

Brock (1999) also discussed the importance of all faculty and administration members working together by concluding that effective mentorship programs require the support of the faculty and all levels of the school's administration. This support includes the superintendent and school board; however, the principal is the pivotal figure whose direct involvement throughout the program's development and implementation is crucial and considered necessary. Rowley (1999) indicated that if administrators and teachers value mentoring and take it seriously, mentoring will attract both caring and committed teachers who recognize the complex and challenging nature of classroom teaching. The opportunity to participate in mentoring may attract experienced teachers who have great hope and optimism for the 
future by their willingness to help a new teacher discover the same satisfaction of teaching that they feel.

Evaluation of a mentorship program is crucial; unfortunately, it is often overlooked and lost at the end of the school year when schedules become rushed and inflexible. An annual evaluation by mentors and mentees is an integral component of a successful program (Brock, 1999). Each program exists within a unique school culture so adjustments may need to be made; there is not a standardized mentorship program. Brock stated that the principal must gather data and use them to determine if program revisions are deemed necessary. Because the needs of first-year teachers are not static, the program needs to adapt to emerging needs perceived by all involved parties: mentors, mentees, and the principal. A formal evaluation provides contemporary information about the teacher mentorship program and process and allows the administrator to make necessary revisions and redirections for the ongoing success of the program (Bey \& Holmes, 1992).

Brock and Grady (1997) stated, "The first year of teaching should be viewed as one step along a continuum of professional development. Beginning teachers require ongoing assistance throughout the year and possibly longer" (p. 54). Once the program is started, it should be carefully maintained in order to be successful. Ongoing evaluations consisting of both quantitative and qualitative measures - interviews, focus groups, and surveys are crucial (David, 2000).

\section{SUMMARY}

Mentorship programs are vital components to a healthy, successful school. Mentor and protégé relationships open the necessary lines of communication and decrease new teacher isolation. "By recognizing the complexities in mentoring, we can view collegial relationships as ongoing, reciprocal, and active forms of professional growth" (Boreen et al., 2000, p. 21). The principal is a key player in the program; he or she needs to take part in the initiation of the program, help define the needs of beginning teachers, select mentors and define mentors' roles, provide staff training, stay personally involved, and evaluate the mentorship program.

\section{REFERENCES}

Anzul, J. C. (2000). Teacher team develops a district mentoring program. Kappa Delta Pi Record, 36(2), 65-67.

Bey, T. M., \& Holmes, C. T. (1990). Mentoring: Developing successful new teachers. Reston, VA: Association of Teacher Educators.

Bey, T. M., \& Holmes, C. T. (Eds.). (1992). Mentoring: Contemporary principles and issues. Reston, VA: Association of Teacher Educators.

Boreen, J., Johnson, M. K., Niday, D., \& Potts, J. (2000). Mentoring beginning teachers: Guiding, reflecting, coaching. York, ME: Stenhouse Publishers. 
Brock, B. L. (1999). The principals' role in mentor programs. Mid-Western Educational Researcher, 12(4), 18-21.

Brock, B. L., \& Grady, M. L. (1997). Principals: The guiding light for new teachers. Momentum, 28(2), 52-55.

Burnett, J. (Ed.). (1967). Aristotle on education. Cambridge, England: Cambridge University Press.

Compayre, G. (1907). Jean Jacques Rousseau: An education from nature (R. P. Jago, Trans.). New York: Thomas Y. Crowell.

David, T. (2000). Teacher mentoring - Benefits all around. Kappa Delta Pi Record, 36(3), 134-136.

DeBolt, G. P. (Ed.). (1992). Teacher induction and mentoring: School-based collaborative programs. Albany: State University of New York Press.

DePaul, A. (2000). Survival guide for new teachers: How new teachers can work effectively with veteran teachers, parents, principals, and teacher educators. Washington, DC: U.S. Department of Education, Office of Educational Research and Improvement.

Drever, J. (1912). Greek education: Its practice and principles. Cambridge, England: Cambridge University Press.

Feiman-Nemser, S. (1996). Mentoring: A critical review. Washington, DC: ERIC Clearinghouse on Teaching and Teacher Education.

Frankena, W. K. (1965). Three historical philosophies of education. Chicago: Scott, Foresman and Company.

Franklin, J. (2002, Winter). The necessary principal: The importance of instructional leadership. Curriculum Update, 6-7.

Gardiner, M. E., Enomoto, E., \& Grogan, M. (2000). Coloring outside the lines: Mentoring women into school leadership. Albany: State University of New York.

Gonzales, F., \& Sosa, A. S. (1993, March). How do we keep teachers in classrooms? The TNT response. IDRA Newsletter, 1, 6-9.

Gordan, S. G. (1991). How to help beginning teachers succeed. Alexandria, VA: Association for Supervision and Curriculum Development.

Halford, J. M. (1998). Easing the way for new teachers. Educational Leadership, 55(5), 33-36.

Head, F. A., Reiman, A. J., \& Thies-Sprinthall, L. (1992). The reality of mentoring: Complexity in its process and function. In T. M. Bey \& C. T. Holmes (Eds.), Mentoring: Contemporary principles and issues (pp. 5-24). Reston, VA: Association of Teacher Educators.

Heath, J. A., \& Yost, R. (2001). Expanding teacher mentorship programs through electronic learning communities. Journal of School Improvement, 2(1), 25-28.

Kyle, D. W., Moore, G. H., \& Sanders, J. L. (1999). The role of the mentor teacher: Insights, challenges, and implications. Peabody Journal of Education, 74(3-4), 109-122.

Lucas, C. A. (1999). Developing competent practitioners. Educational Leadership, 56(8), 45-48.

Lund, L. (1992). Corporate mentoring in U.S. schools: The outstretched hand. New York: The Conference Board.

National Commission of Teaching and America's Future. (1996). What matters most: Teaching for America's future. New York: Author. (ERIC Document Reproduction Service No. ED395931)

Newcombe, E. (1988). Mentoring programs for new teachers. Philadelphia, PA: Research for Better Schools.

Newton, A., Bergstrom, K., Dunne, K., Brennan, N., Gilbert, C., Ibaruen, N., et al. (1994). Mentoring: A resource and training guide for educators. Andover, MA: The Regional Laboratory for Educational Improvement.

Nicholls, G. (1997). Collaborative change in education. London: Kogan Page.

Podsen, I. J., \& Denmark, V. M. (2000). Coaching and mentoring first-year and student teachers. New York: Eye on Education.

Portner, H. (1998). Mentoring new teachers. Thousand Oaks, CA: Corwin Press.

Rousseau, J. J. (1883). Emile: Or concerning education (J. Steeg, Ed.). Boston: D. C. Heath.

Rowley, J. B. (1999). The good mentor. Educational Leadership, 56(8), 20-22.

Steffy, B. E., \& Wolfe, M. P. (1998). The life cycle of the career teacher: Maintaining excellence for a lifetime (Spotlight on Student Success No. 313). Philadelphia, PA: Laboratory for Student Success. Retrieved March 12, 2004, from http://www.temple.edu/LSS/htmlpublications/spotlights/300/spot313.htm 
VanOverbeke, D., \& Vierstraete, S. (2001). Mentoring. Unpublished manuscript, University of South Dakota at Vermillion.

Wood, A. L. (1999). How can teachers become the best? In M. Scherer (Ed.), A better beginning: Supporting and mentoring new teachers (pp. 116-123). Alexandria, VA: Association for Supervision and Curriculum Development.

Sonya Vierstraete is a middle school educator and assistant principal at Holy Redeemer School in Marshall, Minnesota. Correspondence concerning this article should be sent to Dr. Sonya Vierstraete, 203 Bluebird Court, Ghent, MN 56239. 